\title{
Metaphyseal dysplasia-maxillary hypoplasia-brachydacty syndrome
}

INSERM

\section{Source}

INSERM. (1999). Orphanet: an online rare disease and orphan drug data base.

Metaphyseal dysplasia-maxillary hypoplasia-brachydacty syndrome. ORPHA:2504

Metaphyseal dysplasia-maxillary hypoplasia-brachydacty syndrome is characterized by metaphyseal dysplasia associated with short stature and facial dysmorphism (a beaked nose, short philtrum, thin lips, maxillary hypoplasia, dystrophic yellowish teeth) and acral anomalies (short fifth metacarpals and/or short middle phalanges of fingers two and five). It has been described in several members spanning four generations of a FrenchCanadian family. The syndrome is likely to be transmitted as an autosomal dominant trait. 